\title{
Is this study feasible? Facilitating management of pragmatic trial planning milestones under a phased award funding mechanism
}

\author{
Paula Darby Lipman ${ }^{1 *}$, Leanora Dluzak ${ }^{1}$ (I) and Catherine M. Stoney ${ }^{2}$
}

\begin{abstract}
Background: Improving efficiencies in clinical research is crucial to translation of findings into practice and delivery of effective, patient-centered health care. This paper describes a project that monitored pragmatic clinical trials by working with investigators to track achievement of early phase milestones. The National Institutes of Health $(\mathrm{NIH})$ Pragmatic Trials Collaborative Project supported scientifically diverse, low-cost, randomized, controlled, pragmatic clinical intervention trials. Funds were available through a cooperative agreement award mechanism, with the initial phase supporting trial planning and the subsequent 4-year awards funding trial implementation. A coordinating center provided evaluation and administrative support, which included capturing progress toward achieving milestones.
\end{abstract}

Methods: Six funded trials participated in monthly calls throughout the first year to identify and demonstrate metrics and deliverables for each milestone in the Notice of Grant Award. Interviews were conducted with investigators, trial team members, and NIH program officers/project scientists to discuss their perceptions of the impact and value of the management strategy.

Results: Five of six trials transitioned to the implementation phase with milestones ranging from 6 to 15 and quantifiable metrics ranging from 15 to 33, for a total of 121 deliverables. One third of the metrics $(42,35 \%)$ were trial-specific. Trial teams reported that the oversight was onerous but complemented their management strategies; program officers/project scientists found that documentation submitted for review was sufficient to assess trial feasibility; and investigators reported advantages to the phased award mechanism, such as leverage to secure commitments from stakeholders and collaborators, help with task prioritization, and earlier consultation with key members of the trial team.

Conclusions: Implementing systematic approaches to identify milestones and track metrics can strengthen the evidence base regarding time and effort to plan and conduct pragmatic clinical trials. Investigators were unaccustomed to producing evidence of performance, and it was challenging to determine what documentation to provide. Efforts to standardize expectations regarding milestones that mark a significant change or stage in trial development or that represent minimum success criteria may provide guidance for more effective and efficient trial management. A framework with clearly specified metrics is especially critical for transparency, particularly when funding decisions are contingent on both merit and feasibility.

Keywords: Pragmatic trials, Phased award, Trial management, Trial conduct, Milestones, Metrics, Improving efficiencies

\footnotetext{
* Correspondence: paulalipman@westat.com

${ }^{1}$ Westat, 1600 Research Boulevard, Rockville, MD 20850, USA

Full list of author information is available at the end of the article
}

(c) The Author(s). 2019 Open Access This article is distributed under the terms of the Creative Commons Attribution 4.0 International License (http://creativecommons.org/licenses/by/4.0/), which permits unrestricted use, distribution, and reproduction in any medium, provided you give appropriate credit to the original author(s) and the source, provide a link to the Creative Commons license, and indicate if changes were made. The Creative Commons Public Domain Dedication waiver (http://creativecommons.org/publicdomain/zero/1.0/) applies to the data made available in this article, unless otherwise stated. 


\section{Background}

Improving efficiencies across all phases and types of clinical research is crucial to accelerating translation of findings into practice, leading to better delivery of effective, patient-centered care [1-3]. The complexities of conducting clinical trials are well known $[4,5]$, and numerous strategies at multiple levels have been proposed or adopted to address challenges with research design and conduct [6]. This paper describes outcomes of a unique National Institutes of Health (NIH) project that provided management and coordination support for a set of pragmatic clinical trials (RFA-HL-14-019) by working closely with principal investigators (PIs) during the early phase of the trial to identify and track achievement of explicit trial planning milestones.

The NIH Pragmatic Trials Collaborative Project, initiated in 2014 to support scientifically diverse, low-cost, patient-centered, randomized, controlled, pragmatic clinical intervention trials, incorporated several strategies to ensure optimal trial planning and conduct and to promote early identification of potential threats to trial success [7]. The first is the use of cooperative agreements, wherein $\mathrm{NIH}$ program officers (POs) and project scientists (PSs) work jointly with the PIs to serve as a resource and provide scientific guidance throughout the life cycle of the trial. Under this cooperative agreement, members of the project participated in joint activities to gain a better understanding of the struggles and successes of trial planning, explore the significance of stakeholder engagement and other factors, and anticipate potential challenges to meeting patient accrual and data management objectives.

The second strategy to enhance the likelihood of trial success is the phased award mechanism, increasingly used across NIH in recent years, which incorporates processes to identify early phase (i.e., first year) milestones and trials at risk. Funds for the trial implementation phase (i.e., subsequent 4 years) are contingent on administrative review of milestone achievement. Milestones are the qualitative benchmarks of accomplishment of essential goals, and most require a sequence of steps that collectively represent milestone achievement. All trials were required to complete the identified planning milestones within the early phase time period. The milestones reflect the critical start-up steps as delineated in the application, and are incorporated in the Notice of Grant Award (NoGA). The NIH has utilized various approaches to the phased award mechanism, including varying the length of time allotted to complete the planning milestones. Under the NIH Pragmatic Trials Collaborative Project described in this paper, activities expected to be accomplished in the early phase (approximately 12 months) included refinement of existing resources, further development of study partnerships, and finalization of trial protocols. There were sufficient funds for full implementation of all trials. To advance the sponsor's interest in pragmatic trial designs and determine whether they can help to bridge the translation gap, a companion award (RFA-HL-14-020) was made to a coordinating center (awarded to Westat, an employee-owned research organization headquartered in Rockville, MD, USA) to evaluate the funded trials from a process and operational view, particularly during the planning phase, which included assembling appropriate documentation for the administrative review conducted by the NIH [8]. Figure 1 illustrates this process and timeline.

Pragmatic trials conducted in real-world settings have design features that distinguish them from more explanatory trials [9-16]. Given the likelihood of additional unanticipated challenges that may be encountered as investigators secure buy-in from stakeholders and gatekeepers, test feasibility of systems and data collection methods pertaining to primary outcomes, and confirm availability of patient populations, understanding the management of critical start-up activities in the early

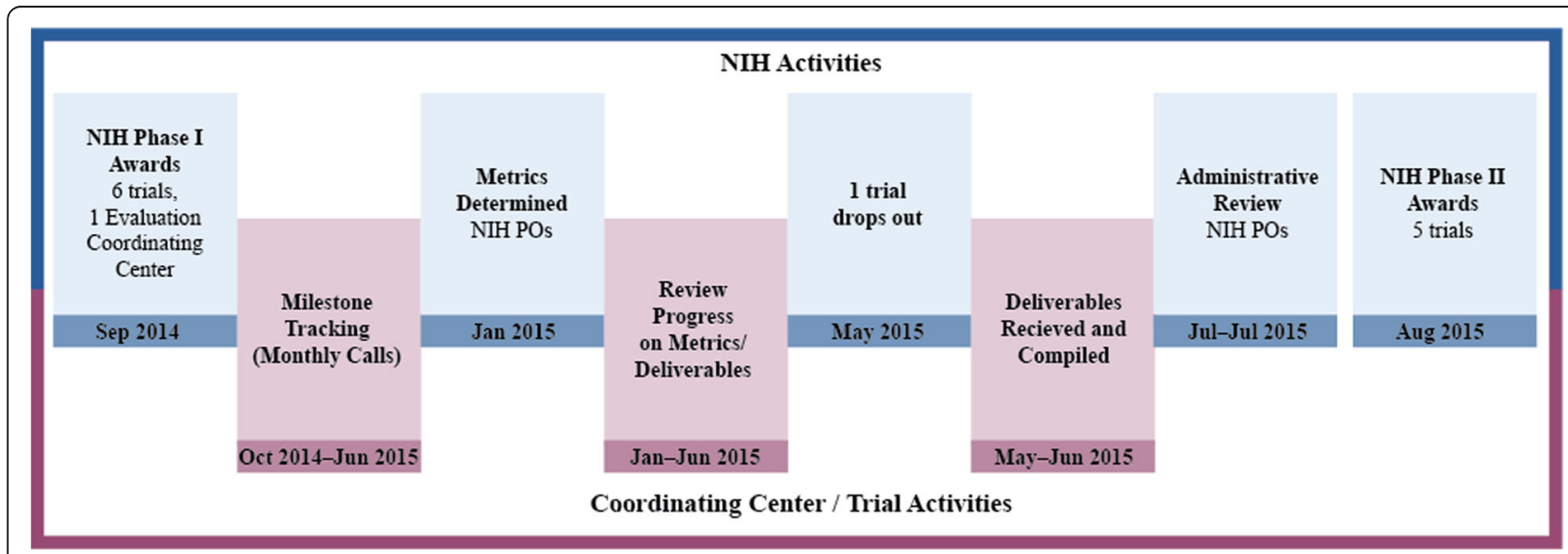

Fig. 1 Planning phase: process flowchart 
phase of more pragmatic trials may be especially relevant to trial designers, sponsors, and research partners [17-20]. While considerable research exists on milestones or features associated with traditional clinical trials [21, 22], only recently have efforts been undertaken to systemically capture critical factors, contingencies, and timelines associated with trial planning for more pragmatic research [23]. Furthermore, the trials funded under this specific initiative had the additional requirement of a lower cost budget compared to many other funding opportunities, such that factors related to management efficiency, workflow, and resource utilization were even more critical [19]. With the support and cooperation of the awardees and their POs, the additional management support provided by the coordinating center facilitated a learning and collaborative platform and offered an opportunity to capture and share lessons learned regarding identifying evidence of achievement of planning milestones under this phased award.

\section{Methods}

Based on the available literature on clinical trial milestones and requirements of the funding announcement, the coordinating center developed a general framework to categorize milestones as Collaborations, Materials and Methods, Clearances, Study Population, Resources, and Patient Information Management. The framework (Table 1) was used to align milestones for each trial, with those appearing to fall outside these categories classified as Trial-Specific.

Six awards were made under this initiative. As is customary under this phased approach, the $\mathrm{NIH} \mathrm{PO}$ assigned to each trial worked with the PI to finalize the

Table 1 Pragmatic trial planning: general framework for milestones and metrics

\begin{tabular}{ll}
\hline Milestones & Illustrative planning phase metrics \\
$\begin{array}{ll}\text { A. Collaborations } & \text { 1. Copies of Memo of Understanding or contracts with } \\
\text { organizations involved in the clinical trial } & \text { 2. Copies of signed agreements of clinical sites (if applicable) } \\
& \text { 3. Copies of letters of support from study champions/investigators } \\
& \text { in relevant delivery locations } \\
& \text { 4. Copies of executed data use agreements }\end{array}$
\end{tabular}

\section{B. Materials and Methods}

Finalize protocol, manual(s) of procedures, data collection forms

\section{Clearances}

Achieve necessary human subject protection approvals and procedures

\section{Study Population}

Evidence of adequate potential study population

E. Patient Information Management

Patient information management

F. Resources

Equipment, staff, training, and budget
1. Copy of Institutional Review Board (IRB)-approved protocol 2. Copy of final manual of procedures

3. Copies of IRB-approved data collection forms (if applicable), including methods for data management and data quality

4. Validated methods to collect data from existing electronic sources (if applicable)

5. Demonstration of methods for integration of data collection forms into electronic resources (if applicable)

1. Copy of IRB approval to conduct clinical trial

2. Copy of IRB-approved informed consent (if applicable)

3. List of Data and Safety Monitoring Board (DSMB) members and copy of DSMB charter

4. Final IRB-approved data and safety monitoring plan

1. Environmental survey of potential study participants (with estimates by site and plan for tracking progress)

2. Recruitment plan with recruitment milestones, alternative strategies, and participant invitation (if applicable)

1. Evidence of feasibility of data collection materials, sources, and processes

2. Documentation of methods for adding patient follow-up information to the trial database

\footnotetext{
1. Documentation of equipment requisitions, availability of adequate and appropriate staff, and budget in line with trial needs

2. Documentation of training needs and training curriculum
} 
planning milestones (September 2014) and subsequently to determine specific metrics associated with each (January 2015). The lag in time was due to the awareness by the project leadership that the indicators needed for the administrative review were at the metric rather than the milestone level. Metrics provide objectively measurable evidence of milestone progress, overall functioning of the trial, and forewarnings about factors that need attention. Tracking achievement on these performance metrics was intended to encourage improvement, increase effectiveness, and manage expectations.

\section{Management support}

From December 2014 (introductory kick-off meeting) through June of 2015, each PI and members of their trial teams participated in recorded monthly conference calls with the coordinating center to discuss progress. These were collaborative 1-h discussions of task prioritization, alignment of metrics with milestones, estimates of completion dates, and negotiation on the type of deliverable to be provided (e.g., screen shots, lists of variables found in data dictionaries, copies of signed agreements). Acceptable forms of documentation included PDFs, Word documents, or Excel files. A tailored tracking form, developed for each trial and updated and redistributed following each monthly call, was used to capture information including date of completion, type of deliverable, and deliverable receipt date. One 2-day in-person meeting was also held toward the end of the first year.

A process was developed to package and deliver documents to the NIH for their internal administrative panel review. Performance documentation was collected using a secure File Transfer Protocol (FTP) server. Submission instructions were provided to the trial teams and included a document naming convention to identify documents and maintain version control as they were received via the FTP server. The coordinating center conducted an adequacy check as materials were collected and worked in collaboration with the trial teams if questions arose. The coordinating center did not assess the documentation on scientific merit but from an operational point of view. A binder for each trial was compiled and included a one-page summary; all the documentation received; and a Reviewer Checklist that itemized each deliverable, provided a column for optional reviewer comments, and requested indication of a satisfactory assessment for each metric. Hard copies of the binders and a flash drive with all documentation were delivered to the NIH where two independent NIH POs (i.e., not the PO of the grant) served as reviewers and provided recommendations for continued funding.

\section{Evaluation}

Recordings and meeting minutes from the 1-h monthly calls, proceedings of the annual 2-day in-person meeting, and semi-structured interviews were the qualitative data for the evaluation. A semi-structured guide was developed for the interviews conducted with PIs and trial team members (August through September 2015) and the NIH POs/ PSs (October 2015) on their perceptions of the impact and value of the management strategy. Data were analyzed by the coordinating center (PDL and LD) using a modified grounded approach [24], with recordings accessed for clarity or to supplement meeting minutes and notes.

\section{Results}

During the early phase of funding, one of the investigators recognized that assumptions about eligibility criteria and availability of patients were flawed, leading to withdrawal prior to the administrative review to pursue a more appropriate funding mechanism. Based on recommendations from the NIH internal administrative review, the remaining five trials [25-29] were approved for implementation funding (summarized in Table 2).

Table 2 Funded trials (Phase II)

\begin{tabular}{|c|c|c|c|}
\hline Trial name & PI (Affiliation)/Sponsor & Trial title & Significance \\
\hline ENGAGES & $\begin{array}{l}\text { M. Avidan, MD (Washington } \\
\text { University)/National Institute on } \\
\text { Aging (NIA) }\end{array}$ & $\begin{array}{l}\text { Electro-encephalograph Guidance } \\
\text { of Anesthesia to Alleviate Geriatric } \\
\text { Syndromes }\end{array}$ & $\begin{array}{l}\text { Reduce post-operative delirium } \\
\text { associated with cognitive } \\
\text { impairment and falls }\end{array}$ \\
\hline HUSH & $\begin{array}{l}\text { D. Buysse, MD (University of } \\
\text { Pittsburgh)/National Heart, Lung, } \\
\text { and Blood Institute (NHLBI) }\end{array}$ & $\begin{array}{l}\text { Pragmatic Trial of Behavioral Interventions } \\
\text { for Insomnia in Hypertensive Patients }\end{array}$ & $\begin{array}{l}\text { Reduce insomnia disorder using } \\
\text { non-drug treatment in primary care }\end{array}$ \\
\hline PART & $\begin{array}{l}\text { H. WANG, MD (University of Texas } \\
\text { at Houston; formerly University of } \\
\text { Alabama at Birmingham) / NHLBI }\end{array}$ & $\begin{array}{l}\text { Pragmatic Trial of Airway Management in } \\
\text { Out-of-Hospital Cardiac Arrest }\end{array}$ & $\begin{array}{l}\text { Identification of best approach for } \\
\text { out-of-hospital cardio-pulmonary } \\
\text { arrest }\end{array}$ \\
\hline PROOFCheck & $\begin{array}{l}\text { M. Gong, MD; O. Gajic, MD (Albert } \\
\text { Einstein College of Medicine of } \\
\text { Yeshiva University)/NHLBI }\end{array}$ & $\begin{array}{l}\text { Prevention of Severe Acute Respiratory } \\
\text { Failure in Patients with PROOFCheck }\end{array}$ & $\begin{array}{l}\text { Prevent acute respiratory failure } \\
\text { leading to organ failure }\end{array}$ \\
\hline REDAPS & $\begin{array}{l}\text { S. Halpern, MD (University of } \\
\text { Pennsylvania)/NIA }\end{array}$ & $\begin{array}{l}\text { Default Palliative Care Consultation for } \\
\text { Seriously III Hospitalized Patients }\end{array}$ & $\begin{array}{l}\text { Determine effectiveness and cost } \\
\text { of inpatient palliative care consult } \\
\text { services }\end{array}$ \\
\hline
\end{tabular}


Table 3 Planning phase: number of metrics by trial

\begin{tabular}{|c|c|c|c|c|c|c|}
\hline & Trial 1 & Trial 2 & Trial 3 & Trial 4 & Trial 5 & Total metrics \\
\hline A. Collaborations & 2 & 4 & 3 & 5 & 3 & 17 \\
\hline B. Materials and Methods & 4 & 8 & 5 & 7 & 4 & 28 \\
\hline C. Clearances & 4 & 5 & 2 & 4 & 2 & 17 \\
\hline D. Study Population & 2 & 2 & 1 & 2 & 1 & 8 \\
\hline E. Patient Information Management & 1 & 0 & 2 & 1 & 1 & 5 \\
\hline F. Resources & 0 & 1 & 0 & 1 & 2 & 4 \\
\hline G. Trial-Specific & 6 & 8 & 20 & 6 & 2 & 42 \\
\hline TOTAL & 19 & 28 & 33 & 26 & 15 & 121 \\
\hline
\end{tabular}

Table 4 Illustrative planning phase trial-specific metrics and deliverables

\begin{tabular}{|c|c|}
\hline Trial-specific metric & Description of deliverable \\
\hline \multicolumn{2}{|l|}{ Training } \\
\hline Train staff on assessment methods & Summary of training with staff \\
\hline Train staff on protocol & Summary of training with staff on the protocol \\
\hline Training sessions completed in intervention settings & Table of trainings completed and planned for future \\
\hline \multicolumn{2}{|l|}{ Stakeholders/partner engagement } \\
\hline Assessment of provider satisfaction with interventions & $\begin{array}{l}\text { Satisfaction survey items and feedback based on data } \\
\text { from five physicians }\end{array}$ \\
\hline Identification of local champions & List of local champions and their letters of support \\
\hline \multicolumn{2}{|l|}{ Data management } \\
\hline $\begin{array}{l}\text { Determine feasibility of obtaining baseline and } \\
\text { 30-day follow-up data }\end{array}$ & $\begin{array}{l}\text { Obtained 30-day follow-up data on } 85 \% \text { of patients } \\
\text { enrolled in pilot }\end{array}$ \\
\hline $\begin{array}{l}\text { Validate capture of all proposed outcomes in a } \\
\text { sample of de-identified patients }\end{array}$ & Description of process to finalize list of outcomes \\
\hline Data form development completion & Copy of data collection forms \\
\hline \multicolumn{2}{|l|}{ Intervention } \\
\hline Create preliminary versions of educational materials & Preliminary draft of educational materials \\
\hline Final adjustments made to interventions & Procedures manual \\
\hline \multicolumn{2}{|l|}{ Recruitment/accrual feasibility } \\
\hline Enroll (subset) of pilot study cohort & Consort diagram summarizing pilot recruitment \\
\hline $\begin{array}{l}\text { Testing and validation in validation cohort: test } \\
\text { candidate model with summary of findings in } \\
\text { derivation cohort }\end{array}$ & $\begin{array}{l}\text { Application of model for patients with and without } \\
\text { an event of concern }\end{array}$ \\
\hline \multicolumn{2}{|l|}{ Information technology/systems } \\
\hline $\begin{array}{l}\text { Fully functional research recruitment alert in } \\
\text { electronic health records }\end{array}$ & $\begin{array}{l}\text { Screenshot of pop-up alert as evidence that system } \\
\text { is functional }\end{array}$ \\
\hline Online intervention ready for deployment & Screen shots of login and modules \\
\hline Web-based data collection procedures in place & Screen shots to capture screening data \\
\hline $\begin{array}{l}\text { Electronic health records data pull methods tested } \\
\text { and validated }\end{array}$ & Three sample Subject Data Tables \\
\hline Web conferencing capabilities for intervention & Minimum technical and support requirements \\
\hline $\begin{array}{l}\text { Development of strategy to automate intervention } \\
\text { into electronic medical records }\end{array}$ & $\begin{array}{l}\text { Flow diagram illustrating how intervention is } \\
\text { integrated with electronic medical records and } \\
\text { other clinical data systems }\end{array}$ \\
\hline $\begin{array}{l}\text { Develop patient identification and automatic ordering } \\
\text { processes in the electronic health records }\end{array}$ & $\begin{array}{l}\text { List of patient eligibility criteria screening; specifications } \\
\text { for automated order }\end{array}$ \\
\hline
\end{tabular}


The number of milestones delineated in the five award notices (NoGAs) ranged from 6 to 15. Most milestones had one or more associated metrics; the total number of metrics ranged from 15 to 33 . One third of the metrics $(42,35 \%)$ were associated with trial-specific milestones. Metrics, rather than milestones, are presented in Table 3, as these were the explicit indicators by which performance and progress were assessed.

\section{Specification of deliverables}

A common challenge in discussions with the trial teams was specifying the deliverable or documentation associated with each metric; this was particularly evident for those that were more unique (e.g., trial-specific) or that represented technological or system-level progress. Occasionally the same deliverable was linked to more than one metric, and this was clearly documented on the tracking form and in the administrative review materials for the NIH. All of these issues were resolved through discussion of options and clear communication with the PIs about expectations.

Table 4 provides a list of trial-specific metrics and a description of their deliverables, further grouped as related to Training (of research staff or interventionists); Stakeholder buy-in or partner engagement; Data management; Intervention refinement and finalization; Recruitment/accrual feasibility; and Information technology (IT) or systems interoperability. Testing feasibility of systems, ensuring buy-in from stakeholders, and assessing intervention acceptability were among the critical achievements required in the planning phase.

Table 4 illustrates that many metrics categorized as trial-specific will test assumptions regarding patient recruitment or accrual, intervention delivery, and management of outcome data, requiring that the associated deliverables demonstrate achievements pertaining to access to electronic health records or functioning of IT and database systems. Descriptions of each deliverable were included in the summary reports provided to reviewers.

\section{Qualitative findings}

Analysis of qualitative data sources, including monthly meeting minutes, the annual in-person meeting transcript, and semi-structured qualitative interviews, indicated that members of the trial teams found the oversight process onerous at times but reflected that it mostly improved or complemented their own management strategies. POs/ PSs benefited from enhanced engagement with the PIs and the opportunity to learn more about pragmatic trial management and implementation of the phased award

Table 5 Summary of Themes from the Planning Phase with Pls, Research Teams, and POs/PSs

\begin{tabular}{|c|c|}
\hline \multicolumn{2}{|l|}{ Oversight (Planning Phase) } \\
\hline $\mathrm{PI} /$ Trial Team & $\begin{array}{l}\text { - Westat and the use of milestones helped with accountability } \\
\text { - Helped the grantees define the milestones } \\
\text { - Encouraged flexibility in interpreting milestones } \\
\text { - Providing documentation was extra work } \\
\text { - Did not have a real need for Westat } \\
\text { - Westat gave unclear guidance }\end{array}$ \\
\hline POs/PSs & $\begin{array}{l}\text { - Westat's role relative to the POs was not always clear } \\
\text { - Input from Westat on grantee milestones provided important clarity to help NIH make decision about funding } \\
\text { - Assistance provided by Westat enabled POs to focus on the science } \\
\text { - Independent review process was very well organized }\end{array}$ \\
\hline \multicolumn{2}{|c|}{ Value of in-person conference } \\
\hline $\mathrm{PI} /$ Trial Team; POs/PSs & $\begin{array}{l}\text { - Everyone who attended the meeting enjoyed it, found it helpful } \\
\text { - Useful to meet other grantees/hear about their trials } \\
\text { - Felt like a community of pragmatic trialists } \\
\text { - Useful to hear the NIH perspective }\end{array}$ \\
\hline POs/PSs & - Useful to hear common description of what pragmatic trials are; everyone on same page \\
\hline \multicolumn{2}{|l|}{ Phased award mechanism } \\
\hline $\mathrm{PI} /$ Trial Team; POs/PSs & $\begin{array}{l}\text { - Planning phase helpful in showing what works, where problem areas are and what is needed to succeed; } \\
\text { good for pilot and feasibility data }\end{array}$ \\
\hline $\mathrm{PI} /$ Trial Team & $\begin{array}{l}\text { - Good, more efficient mechanism for clinical trials; studies with many unknowns } \\
\text { - A way for NIH to be cost-effective } \\
\text { - Provides structure to inexperienced PIs } \\
\text { - Keeps the pace of work up, accountability } \\
\text { - Provides more honest relationship with funding agency }\end{array}$ \\
\hline POs/PSs & $\begin{array}{l}\text { - Significant involvement of NIH in all decision-making } \\
\text { - Mechanism allowed for PO to serve as liaison between trial team and administrative leadership } \\
\text { - Number of milestones should be comparable across grantees (e.g., no more than 15-20) }\end{array}$ \\
\hline
\end{tabular}


mechanism, and reported that the extensive documentation submitted by the coordinating center provided sufficient evidence to assess trial feasibility. Overall, the PIs reported several distinct advantages of the phased award mechanism, including how pressure to demonstrate progress helped to prioritize essential project management tasks, led to earlier engagement with technical and data management staff, and provided additional leverage to secure commitments from external stakeholders and collaborators. Table 5 provides a summary of themes identified in the interviews conducted during the first project year with PIs and POs/PSs, and Table 6 includes select quotes that capture these sentiments.

\section{Discussion}

The observations from this project have the potential to improve the knowledge base regarding macro-level strategies to increase clinical research productivity, thereby demonstrating responsible stewardship of publicly funded science. As this was a unique design under a specific $\mathrm{NIH}$ solicitation with a small number of low-cost trials, future efforts are needed to expand upon our preliminary findings, for example by assessing the association between planning milestones and successful participant recruitment or accrual. However, this effort achieved one of its overarching intentions - early identification of an at-risk trial - as one of the Phase I awardees discovered during this phase that the patient population in their single-site trial was insufficient. Other positive elements included co-management of the planning process, support for generating reliable metrics to assess progress, and a collaborative environment that provided a forum for investigators to share their progress with other researchers in different fields and to communicate in person with their NIH POs/PSs.

Synthesis of lessons from strategies for early identification of trial risk factors can contribute to management guidance and standardization [21], potentially of

Table 6 Illustrative quotes from participants in monthly calls and year 1 in-person project meeting

Value of oversight (planning phase)

Positive aspects of pressure to meet milestones

Phased award mechanism

\section{Comment}

"... this process is very helpful. It's making us think more carefully about our work ... and think about the big picture and where we might be weak."

"If you were just to dive into a busy clinical trial, I think you would cut corners and miss some of those important questions."

"... it paid off in being confident that we could do these things for the long term ... we felt comfortable proceeding with the next iteration."

"You're highly motivated and incentivized to hit those milestones because you know this is a go/no-go. And some of them you have anxiety about because they're beyond your control."

"We had in mind that there were very specific milestones and the evaluation on a monthly basis was helping to keeping [sic] us on track."

"I like the planning year. It gave us more time to devote to having a good plan, which ultimately saves time down the road."

"The project management aspect that Westat provided was useful ... in that way a best practice of research management."

"It helped me in terms of my subcontract sites and my IT."

"When we showed [stakeholders] we were falling off track in any of these areas, it very much focuses us on working on that problem specifically."

"It makes you get started right away, which is a good thing."

"I met with my stakeholders and got their commitment; that was part of the planning year but it wasn't [directly] for patient recruitment."

"We were working with a system we hadn't worked with before that didn't have much research infrastructure ... it was relationship building with the leaders and the informatics team ..."

"... helpful to align institutional leadership."

"... even though I know I hit all of the milestones, this was a new mechanism for me [so I didn't necessarily have confidence re: implementation funds]."

"This is new for many of us ... and it sounds like it actually may be relatively new for some of the agencies as well."

"One of the things I would include would be budgeting [such that] the pilot year could really be a year. Truncating that does apply more pressure."

"... [helpful to] work with the program official [if] milestones are a bit overly ambitious [for the planning year]." 
benefit to both trial designers and funding organizations. Results from our efforts to systematically categorize critical start-up milestones illustrate the need for additional research in this area [30]. The approach used to differentiate milestones specific to the trial from those more likely to be common across all trials suggests that this distinction is not clear-cut. We also speculated but could not confirm whether the relatively large proportion of trial-specific milestones reflects something unique to more pragmatic trials with particular constraints due to their conduct in real-world settings. However, given the overall failure of many trials to meet recruitment or dissemination goals [31, 32], there is value in efforts such as the phased award mechanism to identify critical precursors demonstrating a potential study population adequate to meet the sample size of the trial, and other factors associated with trial feasibility and effective resource utilization.

\section{Conclusions}

Strategies such as cooperative agreements and phased mechanisms are increasingly being adopted and integrated into biomedical funding practices. From the perspective of the investigator, advantages of the phased mechanism include clear delineation of the development time period, as well as specification of critical milestones to be accomplished, which helps prioritize task management, galvanize gatekeepers, and emphasize feasibility testing [33]. The funding institute benefits, as their investment in the trial is potentially less risky, with a clearly delineated process for internal review and clear stopping rules. The methodology developed and implemented by the coordinating center to facilitate management of early phase progress has been disseminated and adapted for similar projects within the NIH.

With regard to the field of pragmatic research more generally, implementing systematic approaches to identify milestones and track metrics can strengthen the evidence base regarding the time and effort required to efficiently conduct and manage large simple trials [4], and this process has been proposed among a set of solutions to improve community-engaged implementation research [34] and the efficiency and effectiveness of clinical trial recruitment planning [35]. Although each awardee in this project was required to provide evidence of completion of metrics, there was considerable variability in number and type required. Future efforts to link early phase management support with trial implementation outcomes can support guidance regarding when flexibility and adaptation versus more rigid adherence to pre-determined milestones is appropriate [13]. Developing and disseminating a classification or framework to guide trial design and review is especially critical for transparency, particularly when funding decisions are contingent on both merit and feasibility [2].

\section{Abbreviations}

DSMB: Data and Safety Monitoring Board; ENGAGES: Electro-encephalograph Guidance of Anesthesia to Alleviate Geriatric Syndromes (trial); FTP: File Transfer Protocol; HUSH: Pragmatic Trial of Behavioral Interventions for Insomnia in Hypertensive Patients; IRB: Institutional Review Board; IT: Information technology; NHLBI: National Heart, Lung, and Blood Institute; $\mathrm{NIH}$ : National Institutes of Health; NoGA: Notice of Grant Award;

PART: Pragmatic Trial of Airway Management in Out-of-Hospital Cardiac Arrest; PI: Principal investigator; PO: Program officer; PROOFCheck: Prevention of Severe Acute Respiratory Failure in Patients with PROOFCheck (Electronic Checklist to Prevent Organ Failure); PS: Project scientist; REDAPS: Default Palliative Care Consultation for Seriously III Hospitalized Patients; RFA: Request for Applications

\section{Acknowledgements}

We thank the Pragmatic Trial Awardees and trial teams; and the National Heart, Lung, and Blood Institute (NHLBI) and National Institute on Aging (NIA) program officers and scientists for their support of our collaborative activities. Mary N. Masters (formally of Westat) played a critical role in the project during this phase.

\section{Funding}

The study is supported by NHLBI Grant 1R01HL125114-01 to Paula Darby Lipman, Ph.D. (Westat); the NHLBI, and the NIH, Bethesda, MD. Dr. Sean Tunis, Center for Medical Technology Policy, is co-investigator.

\section{Availability of data and materials}

The datasets used and/or analyzed during the current study are available from the corresponding author on reasonable request.

\section{Declarations}

The content is solely the responsibility of the authors and does not necessarily represent the official views of the NHLBI, the National Institutes of Health (NIH), or the US Department of Health and Human Services.

\section{Authors' contributions \\ PDL was the primary writer of the manuscript, led the design of the study and evaluation protocol, and conducted the monthly calls. LD contributed to the design of the study, participated in monthly calls, tracked milestones, and contributed to the analysis and manuscript. CMS provided feedback on the study design and evaluation protocol as well as the interpretations and implications of the findings. PDL and LD reviewed and conducted quality control of tables and figures. All authors contributed to writing, reviewing, and approving drafts leading to the final manuscript. All authors read and approved the final manuscript.}

\section{Ethics approval and consent to participate}

The Westat Institutional Review Board (IRB) reviews all studies involving research on human subjects. This study is exempt from IRB review as received from the Chair of the Westat IRB on October 23, 2014 (FWA 00005551). Per [45 CFR 46.101(b5)] and a letter received on October 16, 2014 from Denise Bonds, Medical Officer, NHLBI, this research involves a program evaluation and therefore is exempt from IRB review.

Westat is conducting an evaluation of the methods and processes that contribute to successful pragmatic, low-cost clinical trials. The work involves monitoring the design/planning of these trials and, in years $2-5$, the implementation of the trials. As members of this cooperative agreement, all investigators consented to participate in these activities and, specifically, provided oral consent prior to the conduct of the interviews as reported in this submission.

\section{Consent for publication}

Not applicable.

Competing interests

The authors declare that they have no competing interests.

\section{Publisher's Note}

Springer Nature remains neutral with regard to jurisdictional claims in published maps and institutional affiliations. 


\section{Author details}

${ }^{1}$ Westat, 1600 Research Boulevard, Rockville, MD 20850, USA. ${ }^{2}$ National Heart, Lung, and Blood Institute (NHLBI), National Institutes of Health (NIH), 6701 Rockledge Drive, Bethesda, MD 20817, USA.

Received: 28 September 2018 Accepted: 30 April 2019 Published online: 30 May 2019

\section{References}

1. Baer AR, Bridges KD, O'Dwyer M, Ostroff J, Yasko J. Clinical research site infrastructure and efficiency. J Oncol Pract. 2010;6(5):249-52.

2. Hudson KL, Lauer MS, Collins FS. Toward a new era of trust and transparency in clinical trials. JAMA. 2016;316(13):1353-4.

3. Duley L, Gillman A, Duggan M, Belson S, Knox J, McDonald A, Rawcliffe C, Simon J, Sprosen T, Watson J, Wood W. What are the main inefficiencies in trial conduct: a survey of UKCRC registered clinical trials units in the UK. Trials. 2018;19(1):15.

4. Eapen ZJ, Lauer MS, Temple RJ. The imperative of overcoming barriers to the conduct of large, simple trials. JAMA. 2014;311(14):1397-8.

5. Farrell B. Efficient management of randomised controlled trials: nature or nurture. BMJ. 1998;317(7167):1236.

6. Rubio DM. Common metrics to assess the efficiency of clinical research. Eval Health Prof. 2013;36(4):432-46.

7. Lauer MS, Bonds D. Eliminating the "expensive" adjective for clinical trials. Am Heart J. 2014;167(4):419-20.

8. Lipman PD, Loudon K, Dluzak L, Moloney R, Messner D, Stoney CM. Framing the conversation: use of PRECIS-2 ratings to advance understanding of pragmatic trial design domains. Trials. 2017;18(1):532.

9. Treweek S, Zwarenstein M. Making trials matter: pragmatic and explanatory trials and the problem of applicability. Trials. 2009;10(1):37.

10. Schwartz D, Lellouch J. Explanatory and pragmatic attitudes in therapeutical trials. J Clin Epidemiol. 2009;62(5):499-505.

11. Schwartz D, Lellouch J. Explanatory and pragmatic attitudes in therapeutical trials. J Clin Epidemiol. 1967;20(8):637-48.

12. Patsopoulos NA. A pragmatic view on pragmatic trials. Dialogues Clin Neurosci. 2011;13(2):217.

13. Maclure M. Explaining pragmatic trials to pragmatic policy-makers. Can Med Assoc J. 2009;180(10):1001-3.

14. Tunis SR, Stryer DB, Clancy CM. Practical clinical trials: increasing the value of clinical research for decision making in clinical and health policy. JAMA. 2003;290(12):1624-32.

15. Sox HC, Lewis RJ. Pragmatic trials: practical answers to "real world" questions. JAMA. 2016;316(11):1205-6.

16. Dal-Ré $R$, Janiaud $P$, loannidis JP. Real-world evidence: How pragmatic are randomized controlled trials labeled as pragmatic? BMC Med. 2018;16(1):49.

17. Tickle-Degnen L. Nuts and bolts of conducting feasibility studies. Am J Occup Ther. 2013;67(2):171-6.

18. Whicher DM, Miller JE, Dunham KM, Joffe S. Gatekeepers for pragmatic clinical trials. Clinical Trials. 2015;12(5):442-8.

19. Johnson KE, Tachibana C, Coronado GD, Dember LM, Glasgow RE, Huang SS, Martin PJ, Richards J, Rosenthal G, Septimus E, Simon GE. A guide to research partnerships for pragmatic clinical trials. BMJ. 2014;349:96826.

20. Thabane L, Ma J, Chu R, Cheng J, Ismaila A, Rios LP, Robson R, Thabane M, Giangregorio L, Goldsmith CH. A tutorial on pilot studies: the what, why and how. BMC Med Res Methodol. 2010;10(1):1.

21. Farrell B, Kenyon S, Shakur H. Managing clinical trials. Trials. 2010;11(1):78.

22. Ioannidis JP. Why most clinical research is not useful. PLOS Med. 2016;13(6): e1002049.

23. $\mathrm{NIH}$ Collaboratory website. https://rethinkingclinicaltrials.org/. Accessed 24 Sept 2018.

24. Strauss A, Corbin JM. Basics of qualitative research: grounded theory procedures and techniques. Thousand Oaks: Sage; 1990.

25. Wildes TS, Winter AC, Maybrier HR, Mickle AM, Lenze EJ, Stark S, Lin N, Inouye SK, Schmitt EM, McKinnon SL, Muench MR. Protocol for the Electroencephalography Guidance of Anesthesia to Alleviate Geriatric Syndromes (ENGAGES) study: a pragmatic, randomised clinical trial. BMJ Open. 2016;6(6):e011505. https://doi.org/10.1136/bmjopen-2016-011505.

26. Levenson JC, Rollman BL, Ritterband LM, Strollo PJ, Smith KJ, Yabes JG, Moore CG, Harvey AG, Buysse DJ. Hypertension with unsatisfactory sleep health (HUSH): study protocol for a randomized controlled trial. Trials. 2017; 18(1):256. https://doi.org/10.1186/s13063-017-2001-9.
27. Gong MN, Schenk L, Gajic O, Mirhaji P, Sloan J, Dong Y, Festic E, Herasevich $\checkmark$. Early intervention of patients at risk for acute respiratory failure and prolonged mechanical ventilation with a checklist aimed at the prevention of organ failure: protocol for a pragmatic stepped-wedged cluster trial of PROOFCheck. BMJ Open. 2016;6:e011347. https://doi.org/10.1136/bmjopen2016-011347.

28. Courtright KR, Madden V, Gabler NB, Cooney E, Small DS, Troxel A, Casarett $D$, Ersek M, Cassel JB, Nicholas LH, Escobar G. Rationale and Design of the Randomized Evaluation of Default Access to Palliative Services (REDAPS) trial. Ann Am Thorac Soc. 2016;13(9):1629-39. https://doi.org/10.1513/ AnnalsATS.201604-3080T.

29. Wang HE, Prince DK, Stephens SW, Herren H, Daya M, Richmond N, Carlson J, Warden C, Colella MR, Brienza A, Aufderheide TP. Design and implementation of the resuscitation outcomes consortium pragmatic airway resuscitation trial (PART). Resuscitation. 2016;101:57-64.

30. Treweek S, Littleford R. Trial management-building the evidence base for decision-making. Trials. 2018;19:11.

31. Carlisle B, Kimmelman J, Ramsay T, MacKinnon N. Unsuccessful trial accrual and human subjects protections: an empirical analysis of recently closed trials. Clin Trials. 2015;12(1):77-83.

32. Ross JS, Tse T, Zarin DA, Xu H, Zhou L, Krumholz HM. Publication of NIH funded trials registered in ClinicalTrials.gov: cross sectional analysis. BMJ. 2012;344:d7292.

33. Mickle AM, Maybrier HR, Winter AC, McKinnon SL, Torres BA, Lin N, Lenze EJ, Stark S, Muench MR, Jacobsohn E, Inouye SK. Achieving milestones as a prerequisite for proceeding with a clinical trial. Anesth Analg. 2018;126(6): 1851-8.

34. Mensah GA, Cooper RS, Siega-Riz AM, Cooper LA, Smith JD, Brown CH, Westfall JM, Ofili EO, Price LN, Arteaga S, Parker MC. Reducing cardiovascular disparities through community-engaged implementation research: a National Heart, Lung, and Blood Institute workshop report. Circ Res. 2018; 122(2):213-30.

35. Huang GD, Bull J, McKee KJ, Mahon E, Harper B, Roberts JN. Clinical trials recruitment planning: a proposed framework from the Clinical Trials Transformation Initiative. Contemp Clin Trials. 2018;66:74-9.

Ready to submit your research? Choose BMC and benefit from:

- fast, convenient online submission

- thorough peer review by experienced researchers in your field

- rapid publication on acceptance

- support for research data, including large and complex data types

- gold Open Access which fosters wider collaboration and increased citations

- maximum visibility for your research: over $100 \mathrm{M}$ website views per year

At BMC, research is always in progress.

Learn more biomedcentral.com/submissions 